\title{
Presupuestos teóricos, críticos y literarios del personalismo literario para la enseñanza
}

\section{Literary, critic and theoretical reasons of literary personalism for teaching}

Helena Ospina

Facultad de Letras

Universidad de Costa Rica

\begin{abstract}
Resumen
El objetivo de este artículo es esclarecer lo que entendemos por personalismo literario. La literatura es vista como conocimiento de la realidad y del misterio de la persona humana. Abordaremos los presupuestos teóricos, críticos y literarios de la propuesta, convencidos del valor que tiene para la enseñanza. Helena Ospina describe el itinerario recorrido y sus raíces filosóficas en el personalismo ontológico moderno de Juan Manuel Burgos. La obra literaria se analiza con el método "lúdico-ambital" de Alfonso López Quintás. Y con Gustavo González Villanueva se celebra la obra de arte como goce y captación del misterio.
\end{abstract}

Palabras claves: personalismo literario, Helena Ospina, Juan Manuel Burgos, Alfonso López Quintás, Gustavo González Villanueva

\section{Abstract}

The purpose of this article is to explain what we understand for literary personalism. Literature is considered knowledge of reality and mystery of human person. So, we are going to study literary, critical, and theoretical principles of the proposal, convinced of its value for teaching. Helena Ospina describes her journey and her philosophical roots in modern ontological 
personalism of Juan Manuel Burgos. Literary works are analyzed acording to «lúdico-ambital» method by Alfonso López Quintás. With Gustavo González Villanueva we celebrate masterwork as joy and mystery capture.

Keywords: literary personalism, Helena Ospina, Juan Manuel Burgos, Alfonso López Quintás, Gustavo González Villanueva

\section{Introducción}

- Cómo y por qué se llega al plantea-

$\boldsymbol{6}$ miento en un personalismo literario? Intentaré en mi trabajo dar respuesta a esta pregunta.

La necesidad del pensamiento de un enfoque personalista de la literatura nace, en mi caso concreto, de una vivencia de la creación artística en el seno de mi hogar en Cali, Colombia, en la década de los años cincuenta. De no haber experimentado en mi infancia el goce de las disciplinas del ballet clásico y de la música -en una perspectiva de coherencia-, no se habría jamás "cristalizado" en mi ser una visión específica y particular del arte y de la vida. El porqué dediqué mi esfuerzo intelectual desde 1996 a intentar clarificar esta visión, nació de una convicción personal, profunda, de que para un artista es imprescindible el que permanezca en vigilia toda su vida, escudriñado el origen de su don, la finalidad que intente darle, para que acometa su oficio -su misión- con el goce que procura siempre la búsqueda de la perfección -de su persona y de su arte- que intenta transformar el mundo a partir de la belleza, de la verdad y del bien.

\section{Una particular "vivencia" de la creación artística en mi infancia}

En mi ciudad natal (Cali) mi madre, Georgina Garcés Martínez - con la anuencia de mi padre Eduardo Ospina Delgado- se esforzó por crear un ambiente cultural para mis hijos y los de sus amistades. ¿Qué la motivó? Lo que había vivido en sus años de estudio en París, Bruselas e Inglaterra antes de la Segunda Guerra Mundial. Obligada a regresar a su patria por la guerra, le quedaban dos caminos: "quejarse" por haber perdido ese enclave cultural privilegiado o crear un "ambiente" que facilitara el acceso a la cultura a muchas personas. A Cali habían llegado muchos artistas europeos en exilio. Mi madre les procuró que pudieran ganarse dignamente la vida con su talento. Así fue como nuestro hogar se transformó en un centro cultural donde se impartían clases de ballet clásico, piano, historia del arte...

¿Qué fue lo que percibí en esta primera experiencia artística de mi infancia y adolescencia desde los seis años de edad hasta los dieciséis? La mejor forma para describirla es la palabra "tono humano". Había coherencia entre lo que se vivía y lo que se aprendía. Se trataba de aspectos que tenían que ver con la formación del carácter de la 
persona: la exigencia de ambas disciplinas -ballet clásico y piano- era ardua.

Implicaba horarios de clases, prácticas adicionales cuando se realizaban performances, y estudio personal en casa. Todo esto se sumaba a la escolaridad formal de los estudios de primaria y secundaria. Era como cursar tres carreras a la vez. ¿Qué ganancia formativa hubo? La del aprovechamiento del tiempo, la de organización de este y la del goce que procuraba que era mayor que la "tensión" experimentada en el ejercicio de estas disciplinas.

¿En qué consistía esa coherencia? En la vivencia de un trato especial entre profesor y alumno que tenía que ver con el respeto y la experiencia. En el dominio del carácter personal cuando se superponían tareas que pedían llevar a perder la paciencia o a desistir de hacer lo que se tenía que hacer cuando se tenía que hacer. Muy tempranamente comprendí que el arte tenía que ver con la vida, y que el arte podía llevar a "escuchar" una manera de pensar y de actuar.

\section{Una "visión" temprana de la unidad}

La vivencia del carácter formatico de la creación artística -que experimenté en las disciplinas que estudiaba- me llevó a intuir que la conexión entre "arte y persona" era importante. La filósofa alemana Edith Stein afirmaba -como educadora que era- que en la infancia es donde se consolidan las "imágenes artísticas" que permanecerán luego para siempre en la vida de las personas. Expuse este trabajo en el año 2006 en un coloquio literario en Colombia: "Mi trilogía poética sobre el esplendor de la belleza-Splendor formae,
Aplendor Personae, Splendor gloriae- a la luz del pensamiento de Edith Stein". También expuse, en otro congreso de Lenguas Modernas en Costa Rica la importancia que tiene la familia en la forja de la cultura de la persona: "Condiciones esenciales para el crecimiento de la cultura según T.S. Eliot".

La "visión" de una conexión entre arte y vida exige que uno clarifique en qué consiste y busque en otros artistas -su manera de vivir de crear-, para ver si la intuición tiene asidero, si es relevante, para luego intentar una "formulación" que se aproxime a lo visto y vivido.

El primer intento de formulación "teórica" de esta visión lo presenté en el año 1996 en el Congreso "Cultura Europea" de la Universidad de Navarra: "Arte y persona: implicaciones de la noción y de la realidad 'unidad de vida' de Josemaría Escrivá en la persona y en el artista". La confirmación "práctica" de esta unidad existente entre arte y persona la experimenté en el Workshop sobre Artistic Creativity (Hans Thomas) del Congreso "La grandeza de la vida ordinaria", celebrado en Roma para conmemorar el centenario del nacimiento de Escrivá. Allí tuve la oportunidad del "encuentro" y del "diálogo" con los artistas que dieron el testimonio de cómo las enseñanzas de San Josemaría habían influido en su vida y en su trabajo artístico. Todos estábamos conscientes de que Escrivá no había escrito sobre arte, pero sus libros y su vida constituían una invitación para vivir a plenitud la vida personal $\mathrm{y}$, en el caso nuestro, el oficio artístico. Allí presenté mi trabajo sobre su best seller: "Camino: una guía de audición para los 
artistas. Concierto para piano no. 1 en sol mayor, op. 999".

En Roma, descubrí la existencia de un grupo interdisciplinar de investigadores sobre "Poética \& Cristianismo" de la Facultad de Comunicación de la Pontificia Universidad de la Santa Cruz. Empecé a vincular a este grupo y desde el año 206 hasta la fecha comienzo a presentar trabajos y a estudiar las Actas de sus congresos, para intentar desentrañar las características del vínculo existente entre "Poética \& Cristianismo" que iluminarían mi vínculo entre "Arte \& Persona".

Lo primero que me llamó la atención fue el signo "\&" que unía los dos conceptos de Poética y Cristianismo. Uno de los integrantes del grupo de investigación, Juan José García-Noblejas, nos explicó el sentido del signo " $\&$ ". Se trataba de buscar la vertebración entre Poética \& Cristianismo. Para esto no servía la conjunción " $y$ ". No se trata de Poética "y" Cristianismo, porque lo que se busca es la "conexión íntima" que puede existir entre los valores cristianos y la poética (en todas las expresiones artísticas).

En 2006, diez años después de mi presentación "teórica" de la unidad entre arte y persona, presenté en Roma el trabajo: "Arte y persona en Victoria Ocampo (1890-1979)". Ella me confirmó, como escritora, "la nostalgia" profunda existente entre arte y vida. Cuando ella se vio confrontada por la "perfección artística" de la obra literaria de Rabindranath Tagore y la "plenitud humana" de Gandhi, se preguntó a sí misma: ¿a quién elijo: a Tagore o a Gandhi? Apostó por Gandhi.
Prefirió la perfección de la vida a la perfección de la obra de arte. En un ensayo que escribí ¿Arte y santidad? El drama interior de Victoria Ocampo, busqué hacer ver que se puede y se debe buscar simultáneamente la perfección en la vida y en el oficio artístico. No tiene por qué existir una contradicción. Mi tío abuelo, el gran humanista latinoamericano, el Padre Eduardo Ospina S.J. (1891-1965), afirmó al respecto lo siguiente:

Hay una relación íntima entre la elevación de la virtud y la elevación del arte, entre la armonía sobrenatural y la armonía visual: la vida santa es la mayor belleza y, si se manifestara visiblemente, sería la obra maestra del arte (Arte y persona en Eduardo Ospina 23).

\section{El planteamiento del personalismo literario}

Llegan a diez los trabajos que he presentado en congresos nacionales e internacionales desde 1996 sobre esta vertebración entre arte y persona, estudiando artistas de Guatemala, Colombia, Argentina, Alemania, España, Polonia, Norteamérica y Rusia:

1. "Carta de navegación para la Glosa del amor bien pagado [Gustavo González Villanueva]".

2. "La honda y el arpa en la poesía de David Mejía Velilla”.

3. "Arte y persona en Victoria Ocampo (1890-1979)".

4. "Poesía y vida en la persona y en la obra del padre Eduardo Ospina".

5. "Mi trilogía poética sobre el esplendor de la belleza -Splendor Formae, Splendor Personae, Splendor Gloriae- a la luz del pensamiento de Edith Stein". 
6. "Eros y ágape en la poesía de Enestina de Champourcin".

7. "Arte \& Persona en Bartolomé Lloréns (1922-1947)".

8. "Mousiké [Karol Wojtyla] y Cantata a las Artes [Helena Ospina]. La búsqueda de una poética de la unidad".

9. “Art \& Person in Flannery O'Connor: A Lifetime Endeavor (1925-1964)".

10.'Pavel Glorenski: La búsqueda de una poética personalista de la unidad. El arte de la vida".

A raíz de estos trabajos vislumbré la necesidad de hacer la sistematización de un planteamiento que denominaría "personalismo literario". Me vinculé a la Asociación Española de Personalismo (AEP) porque quería estudiar los rasgos del personalismo ontológico moderno que el presidente de la Asociación, Juan Manuel Burgos, estaba desarrollando. ¿Por qué busqué esta vinculación? Porque había descubierto que en los nueve Encuentros Mesoamericanos "Escritura-Cultura" (proyecto que coordiné del 2006 al 2014 para la Escuela de Lenguas Modernas de la Universidad de Costa Rica) latía un "corpus teórico" sobre "la centralidad de la persona humana" para la creación y la crítica literaria.

Uno de los impulsores y miembros del comité científico, Gustavo González Villanueva, había ido planteando "año tras año" el desarrollo de temas por estudiar que hablaban de esa estrecha relación y responsabilidad social de la persona del artista frente a su obra:

2006 Clásicos, contemporáneos e inéditos $2007 \mathrm{El}$ escritor frente a su obra
2008 Proyección social y responsabilidad del autor

2009 Editores y escritores. Dos protagonistas inseparables

2010 Escritores y lectores. Persona y personaje: derechos y deberes

2011 La comunicación de la belleza a través de la palabra: su actor y su receptor

2012 Pensamiento - Literatura - Independencia

2013 Nueva literatura para un siglo nuevo: El Popol Wuuj, el libro del amanecer 2014 Vivir la literatura, vivir la cultura: la función del escritor, la función de la crítica

Con el estudiante de Maestría en Literatura Latinoamericana e investigador Gabriel Quesada Mora, me lancé en congresos a hablar de la literatura "en clave personalista". Todas estas investigaciones las editamos y publicamos en la obra colectiva Literatura y personalismo: una mirada profunda. El filósofo español Alfonso López Quintás centró el tema con su ensayo sobre "La mirada profunda".

En noviembre de 2014, Juan Manuel Burgos (presidente de la Asociación Española de Personalismo) vino a Costa Rica con motivo de un congreso. Visitó la editorial Promesa, conocedor de nuestras publicaciones de "literatura personalista". Me invitó a coordinar el área de Estética y Literatura para el próximo congreso de la AEP que se celebraría en Loja, Ecuador. Allí pronuncié la conferencia plenaria sobre "Arte \& Persona: una propuesta teórica y un método de análisis personalista para la estética y literatura". El enfoque "personalista" en la estética y en la literatura había recibido el "espaldarazo" de la Asociación para que continuáramos con su gradual "clasificación” y desarrollo. 
Habíamos descubierto, en la estética de López Quintás con su método "lúdico-ambital", el camino para abordar el estudio de la obra de arte que tuviera este enfoque "desde la persona" con su clásica distinción entre "objeto" y "ámbito".

Los presupuestos teóricos de este abordaje los describirá Jorge Mario Cabrera (filósofo y filólogo) en su intervención. A partir de los "niveles de realidad" que López Quintás explica, Cabrera valorará varias obras de la literatura universal, con el fin de mostrar la validez del enfoque y la riqueza de su aplicación para la enseñanza.

Los presupuestos críticos del Personalismo literario los presentará Gabriel Quesada Mora, mostrando la riqueza de los conceptos "objeto-ámbito", "significadosentido", "vértigo-éxtasis"..., entre otros, para el estudio de la novela Apolonio: un politico dentro de la posible realidad de América Latina del guatemalteco Gustavo González Villanueva.

A finales de octubre de este año presenté en Cracovia (Polonia) en el Congreso, organizado por la Universidad Ignatianum, Word in Education: Moral Upbringing through Arts and Literature, mi trabajo "A 'poetics of unity' between art \& person. The role of art san literatura in the artist's personal information".

El primer día en el debate inaugural del congreso describí el "itinerario" vital de mi "poética de la unidad": el origen de ella y la constante búsqueda de "grupos de la investigación" internacionales que sintonizaran con esta visión de persona, arte y cultura. Este Congreso lo organizaba precisamente un grupo de investigadores sobre PROSOPON: TRIVIUM ("Family, Education and Inclusive School) que dirige Marcin Kazmierkzak desde la Universidad Abat Oliva - CEU de Barcelona.

El segundo día del Congreso, la educadora y filóloga Inger Enkvist (Keynote speaker) de la Universidad de Lund (Suecia) leyó su trabajo sobre "Ethics in literary criticism studied in connection with the work of Jane Austen". El párrafo inicial de su intervención fue decisivo para seguir motivándome en el desarrollo del "enfoque personalista" de la literatura y de la crítica literaria. Enkvist afirma:

Structuralism has left its mark on literary criticism. Today's literary scholars are not supposed to think of the writers as having a purpose with their writing or to look for connections between the authors' lives and their work. Furthermore, the characters should not be seen as metaphors for real persons but as functions or parts of a structure. Any discussion of whether a literary work conveys a positive worldview is rejected as naïve and not scientific.

There are however a small number a commentators who oppose this view of art, artists and scholarship. In On moral fiction (1978), the American critic John Gardner states: "Art should be moral, and critics should say if it is" (18). For him, if there is no truth and no beauty, then art becomes irrelevant. Art has a place in our lives, and one of its purposes is to help us keep track of what we know. Gardner also points out that Christian values have not been proven wrong but have only fallen out of fashion. 
Al regresar a Costa Rica acometí de nuevo el estudio de las categorías "personalistas" que Juan Manuel Burgos plantea en sus dos artículos recientes del 2015: "El personalismo ontológico moderno: I Arquitectónica. II. Claves antropológicas". Esto, con el fin de seguir "clarificando" los matices "personalistas" de mis presupuestos literarios.

Como lo mencioné anteriormente, los Encuentros Mesoamericanos "Escritura-Cultura" (que coordiné para la Universidad de Costa Rica del 2006 al 2014), fueron el acicate definitivo para ir precisando el desarrollo de mi "poética de la unidad". En estos Encuentros - entre escritores, artistas y críticos- latía la convicción de repensar la literatura y la crítica literaria "desde la persona".

Enumeraré algunos de los "rasgos personalistas" que señala Burgos, y que coinciden con lo investigado y vivido durante nuestros Encuentros, cuyos trabajos se encuentran publicados en las Actas de estos:

- La centralidad de la persona,

- el giro del "qué" al quién",

- la efectividad y la subjetividad,

- la autoconciencia,

- la libertad como autodeterminación,

- la relación interpersonal,

- la sustitución del "yo-ello" por el "yo-tú".

- el carácter narrativo de la existencia humana,

- la responsabilidad social.

Estos rasgos señalados por Burgos nos permitían volver a rescatar la "unidad" autor-texto-lector. La literatura es conocimiento de la realidad (Bergamino), es autoconocimiento conlleva la responsabilidad de una proyección social. La literatura no es neutra. La obra de arte influye para bien o para mal a lo largo del tiempo. La literatura es comunicación personal, de persona a persona a través del "texto"; es capaz de estableces vínculos; de penetrar en la intimidad del ser humano y de su entorno. El giro que propone el personalismo del "qué" al "quién" libera la creación y la crítica literaria de la reducción de la obra al "texto". En el enfoque personalista, "texto-autor-lector" son capaces de entrar en diálogo, y este encuentro es configurador de la identidad personal y colectiva. Pensar "desde la persona" - con categorías personalistas- se convierte entonces en el "gozne" y "quicio" del enfoque creativo y crítico. Es una literatura "pensada desde la persona" y "para la persona". Es un enfoque crítico que hace trascender la "materia prima" del "texto" hacia el horizonte insospechado del misterio, donde, como afirma González Villanueva, la cultura se torna fiesta:

La cultura es fiesta. Una fiesta continuamente celebrada por la luz o por la sombra; por la mañana, por el mediodía o por la tarde; por la niñez, la juventud, la madurez o por el otoño o el invierno. La persona que cultiva siempre tiene estaciones, y cada estación tiene su música y su encanto. Es un verso, una melodía de antaño o de hoy, un refrán, un dicho, en definitiva la palabra -o más preciso: el logos- que suena con armonía de tormenta o de bonanza. Pero siempre armonía. La persona y su melodía, la persona y su tonada (En Revista Académica, Número Especial, 2016. Versión digital). 


\section{Conclusión}

La propuesta de un "enfoque personalista" de la creación y de la crítica literaria nace de la convicción: "la centralidad de la persona para la cultura”. Esta intuición surgió en mi infancia, gracias al ambiente cultural y educativo de mi familia. Esta visión inicial de la cultura se convirtió a lo largo de mi vida una misión: buscar a artistas y entrar en contacto con grupos de investigación que me permitieran validar y desarrollar "una poética de la unidad entre arte \& persona". Desde hace más de veinte años vengo "cruzando fronteras literarios y culturales" -lema de este congreso- en este sentido. En la mesa redonda buscamos presentarles los presupuestos teóricos, críticos y literarios de esta propuesta que consideramos enriquecedora para la enseñanza, porque abre la perspectiva de la cultura hacia la búsqueda, no sólo de la perfección de la obra de arte sino también del artista, como fuente de gozo y asombro ante el misterio del ser humano.

4-XI-2016, San José, Costa Rica

\section{Referencias}

Bergamino, Federica (comp.). Alicia del espejo. Literatura y conocimiento de la realidad. San José: Promesa, 2014. 308 p. impreso.

Burgos, Juan Manuel. "El personalismo ontológico moderno. I. Arquitectónica". Quién. Revista de Filosofía personalista. Número 1 (2015): 9-27. Impreso.

. "El personalismo ontológico moderno. II. Claves antropológicas". Quién. Revista de filosofía personalista. Número 2 (2015): 7-32. Impreso.

Cabrera Valverde, Jorge Mario. "Reseña crítica: Campo cuajado. Apuntes sobre Arte \& Persona de Helena Ospina”. Escritores y lectores. Persona y personajes. Derechos y deberes. Actas del V Encuentro Mesoamericano "Escritura-Cultura" $y$ del III Coloquio Escritoras y Escritores Latinoamericanos. Ed. Helena Ospina. San José, C.R: Universidad de Costa Rica; Promesa, 2011- 482487. Impreso.

. "Reseña crítica: Literatura y personalismo. Una mirada profunda de Helena Ospina y Gabriel Quesada Mora (eds.). En Quién, Revista de Filosofía personalista. Número 1 (2015): 184-486. Impreso.

Enkvist, Inger. "Ethics in literary criticism studied in connection with the work of Jane Austen". Word in Education: Moral Upbringing through Arts and Literature. 27 al 28 oct. 2016. Cracovia: Universidad Ignatianum.

González Villanueva, Gustavo. "Cultura y misterio". Revista Multidisciplinaria Semestral. Número Especial (2016): 15-19. Web. 3 nov. 2016. http://www.saber.ula.ve/bitstream/123456789/42368/1/2.pdf

López Quintás, Alfonso. El poder transfigurador del arte. San José: Promesa, 2003. Impreso.

Ospina, Helena. “A 'poetics of unity' between art \& person. The role of arts and literatura in the artist's personal formation". Word in Education Moral Upbringing through Arts and 
Literature. 27 al 28 oct. 2016. Crocavia: Universidad Ignatianum. . "Arte \& Persona en Bartolomé Lloréns (1922-1947)”. Ficción y valores en la literatura hispanoamericana. Actas del IV Coloquio Internacional "Literatura Hispanoamericana y sus Valores". 6 al 8 nov. 2008. Chía: Universidad de La Sabana, 2009. 103-118. Impreso.

. "Arte \& Persona: la búsqueda de una poética de la unidad". Escritores y lectores. Persona y personajes. Derechos y deberes. Actas del V Encuentro Mesoamericano "Escritura-Cultura" y del III Coloquio Escritoras y Escritores Latinoamericanos. Ed. Helena Ospina. San José, C.R: Universidad de Costa Rica; Promesa, 2011. 126138. Impreso.

. "Arte y persona en Victoria Ocampo (1980-1979)". Il ritorno a casa. Poética \& Cristianesimo. 28 al 29 abril 2005. Ed. Rafael Jiménez Caraño. Roma: Pontificia Università della Santa Croce, 2006. 375-383. Impreso.

. Arte y persona en Eduardo Ospina. San José: Promesa, 2005. Impreso.

. "Arte \& Persona: una propuesta teórica y un método de análisis personalista para la Estética y la Literatura". Revista Multidisciplinaria Semestral. Número Especial (2015): 33-43. Web. 1 oct. 2016 http://www.saber.ula.ve/bitstream/123456789/41185/1/articulo3.pdf
. "Art \& Person in Flannery O'Connor: A Lifetime Endeavor (1925-1964)". Ragione, Fiction e Fede. Convegno internazionale su Flannery O'Connor. POetica \& Cristianesimo. Convegni Biennali della Facoltà di Comunicazione Sociale Istituzionale. 20 al 22 abril 2009. Roma: Pontificia Università della Santa Croce, 2011. 305-312. Impreso. -AArte o santidad? El drama interior de Victoria Ocampo. Prólogo Víctor Valembois. San José: Promesa, 2006. Impreso. Campo cuajado. Apuntes sobre Arte \& Persona. San José: Promesa, 2010. Impreso.

- "Carta de navegación para la Glosa del amor bien pagado [Gustavo González Villanueva]". Encuentros literarios, filosóficos y artísticos. IV Jornada Nacional de Reflexión Omar Dengo. Dir. Luis Fernando Araya Rivas. San José: Promesa, Universidad Nacional, Centro Cultural Español, 1997. 177-238. Impreso.

"Condiciones esenciales para el crecimiento de la cultura según T.S. Eliot". Revista de Lenguas Modernas. Universidad de Costa Rica. 23 (julio-diciembre 2015): 13-24. Impreso.

. "Eros y ágape en la poesía de Ernestina de Champourcin". Personaje literario hispanoamericano como un valor. Actas del III Coloquio Internacional "Literatura Hispanoamericana y sus Valores". Universidad de Costa Rica. 16 al 17 de 
agosto 2007. Chía: Universidad de La Sabana, 2008. 235-246. Impreso. . "La honda y el arpa en la poesía de David Mejía Velilla". Pensamiento y cultura. Revista del Instituto de Humanidades. Universidad de La Sabana, Chía, Colombia 5 (2002): 113-120. Impreso.

. "La unidad de fondo y forma en la obra literaria". Nueva literatura para un nuevo siglo. Actas del VIII Encuentro Mesoamericano "Escritura-Cultura" y del VI Coloquio Escritoras y Escritores Latinoamericanos. Ed. Helena Ospina. San José, C.R: Universidad de Costa Rica; Promesa, 2014. 324328. Impreso.

. "Mi trilogía poética sobre el esplendor de la belleza -Splendor Formae, Splendor Personae, Splendor Gloriae- a la luz del pensamiento de Edith Stein". Miradas axiológicas a la literatura hispanoamericana. Actas del II Coloquio Internacional "Literatura Hispanoamericana y sus Valores”. 7 al 9 set. 2006. Ed. Bogdan Piotrowski. Bogotá: Universidad de La Sabana, 2007. 355-372. Impreso.

. "Mousiké [Karol Wojtyla] y Cantata a las Artes [Helena Ospina]. La búsqueda de una poética de la unidad". Congreso Internacional Legado de Juan Pablo II El Magno. Red Internacional de Investigación Juan Pablo II El Magno, Escuela de Comunicación Social y Periodismo de la Universidad Sergio Arboleda, Bogotá, Colombia. 19 al 29 feb. 2010.
" "Pavel Florenski: La búsqueda de una poética personalista de la unidad. El arte de la vida". V Convegno Poetica \& Cristianesimo "Escritores del Siglo XX y misterio cristiano". Pontificia Universidad de la Santa Cruz, Roma 5 al 6 mayo 2011. "Persona y cultura". Nueva literatura para un nuevo siglo. Actas del VIII Encuentro Mesoamericano "Escritura-Cultura" $y$ del VI Coloquio Escritoras y Escritores Latinoamericanos. Ed. Helena Ospina. San José: Universidad de Costa Rica; Promesa, 2014. 1922. Impreso.

. "Poesía y vida en la persona y en la obra del padre Eduardo Ospina". Literatura Hispanoamericana y sus Valores. Actas del I Coloquio Internacional. 20 al 22 set. 2004. Ed. Bogdan Piotrowski. Chía: Universidad de La Sabana. 2006. 309-320. Impreso.

Ospina, Helena y Quesada, Gabriel. Literatura y personalismo: Una mirada profunda. San José: Promesa, 2014. Impreso.

Quesada Mora, Gabriel. “Alfonso López Quintás: La creatividad del pensamiento y la rigurosidad del estudio profundo de los textos literarios". La comunicación de la belleza a través de la palabra: su actor y su receptor. Actas del VI Encuentro Mesoamericano "Escritura-Cultura” y del IV Coloquio Escritoras y Escritores Latinoamericanos. Ed. Helena Ospina. San José, C.R: Universidad de Costa Rica; Promesa, 2012. 83-89. Impreso. 
"Hacia una mirada personalista de la literatura". Pensamiento. Literatura. Independencia. Actas del VII Encuentro Mesoamericano "Escritura-Cultura" y del $V$ Coloquio Escritoras y escritores Latinoamericanos. Ed. Helena Ospina. San José, C.R: Universidad de Costa Rica; Promesa, 2013. 153171. Impreso.
Thomas, Hans (ed.). Artistic Creativity. Rome: Edizioni Università della Santa Croce, 2003. Impreso. 
